\title{
Katy Bennett
}

University of Leicester, UK

\section{Allan Cochrane}

The Open University, UK

\section{Giles Mohan}

The Open University, UK

\section{Sarah Neal}

University of Surrey, UK

\begin{abstract}
This paper contributes to research on urban multiculture and debates as to how people routinely live and experience ethnic diversity in their everyday lives. This research takes an 'unpanicked' approach to multiculture that sits differently to, although not unaffected by, multiculturalism as policy objective and those debates around multiculturalism that variously celebrate cultural difference or construct it through crisis talk. Critical to this paper are the routine phenomenologies of multiculture and the everyday practices, competencies and skills of young people attending college. Because of their diverse intakes and the openness of young people to difference, colleges are key sites within which urban multiculture is experienced and through which it is defined. Based on participant observation, repeat in-depth discussion groups and interviews, the focus of this paper is young adults attending post- 16 colleges and schools in three ethnically diverse urban locations. Colleges and schools are urban spaces that mediate sociality and student experience but are also woven into the wider urban setting in which they are placed. The paper explores the skills and competencies that young adults develop to negotiate college and we particularly focus on their use of jokes and the exercise of restraint to get along with others.
\end{abstract}

\section{Keywords}

community, competencies, diversity, education, educational spaces, multiculture, young people

Corresponding author:

Katy Bennett, University of Leicester, Geography, Bennett Building, University Road, Leicester LEI 7RH, UK.

Email: kjb33@le.ac.uk 
The make-up of England's urban population has been transformed over the last two decades. As the results of the 2011 Census confirm, England's cities have become increasingly diverse (Jivrav, 2012; Office for National Statistics, 2012). Responses to these shifts have been uncertain. Often, ethnic difference and cultural diversity are studied as 'problems', or given a high profile when conflict emerges. While there has been a policy tradition of celebrating diversity, in recent years the notion of 'multiculturalism' has increasingly been incorporated into crisis talk (Lentin and Titley, 2011). Drawing on wider debates (see, for example, Amin, 2002; Gilroy, 2004; Heath and Demireva, 2014; Noble, 2013; Valentine, 2008; Vertovec, 2007; Wise and Velayutham, 2009), we have argued elsewhere (Neal et al., 2013) that it is instead necessary to take an 'unpanicked' approach, one that starts from the existence of multiculture as a 'commonplace' (Wessendorf, 2014) demographic experience and opens up the possibility of convivial social relations, defined through light touch sociality and togetherness across ethnic difference involving encounter, engagement, negotiation, competencies and sometimes tensions too as people live multiculture (Neal et al., 2015a; Nowicka and Vertovec, 2014; Wessendorf, 2014; Wilson, 2011; Wise, 2009).

Our use of the term 'living multiculture' in this context is deliberate, in part to distinguish our approach from those that focus on multiculturalism as a policy object, but also because the debates around multiculturalism have been distorted whether through the lens of celebratory or crisis talk (Nayak, 2012). Our work also draws on recent literature around the notion of super-diversity, which identifies increasing cultural and ethnic diversity and the ways in which these are woven through other forms of diversity including socioeconomic differentiation, different patterns of migration and settlement, immigration status and political mobilisation
(Noble, 2009; Vertovec, 2007). But we use the term 'living multiculture' both because it seems to us to offer a more open and unfinished range of possibilities, in which the prospect of intersectionality (across class, gender and sexuality as well as ethnicity) is as important as any implicit or explicit assumptions that we are working with sets of more or less fixed cultures, however diverse they may be, and because the everyday we are exploring is rather more mundane and persistent than the prefix 'super' seems to imply.

Although the main focus of the paper is on ethnicity and ethnic difference, it will be clear from the arguments that follow and the evidence we present that issues of gender and class (as well as geography) are deeply embedded in the social relations that we discuss. We are interested in looking at those settings in which cultural diversity, ethnic difference and social interaction are part of the everyday and the routine, as well as being at times troubled and uncertain. We are also concerned with everyday practices of accommodation and negotiation that generate 'unpanicked' multiculture (Noble, 2009). In other words, our emphasis is on how multiculture works in and is defined through practice.

Approaching issues in this way implies 'attending to the ordinary social spaces within which people of different backgrounds encounter one another, and the mundane practices they construct and draw on to manage these encounters' (Harris, 2009: 188). Like Amin (2012) we seek to move beyond simple stories of encounter to understand processes of negotiation, of coproduction as well as co-presence. This is a perspective that tries to move beyond the notion of multiculturalism as a policy or ideology and beyond a focus on 'ethnic' groups or individuals and their capacity to adapt.

We are particularly interested in the interpersonal resources and techniques that people 
draw upon as they routinely live multiculture and the paper explores people's crafting of the skills involved in negotiating place and different others (Noble, 2013; Sennett, 2012; Wilson, 2011, 2014; Wise, 2009). Competencies refer here to the skills, knowledge and practices that people use and develop as they mix with others, ease social relations and attempt social repair in the context of misunderstanding or tensions (Neal and Vincent, 2013).

This paper is informed by research which draws on fieldwork in Hackney (a London borough), Milton Keynes (a new town on the edge of southeast England), and Oadby (a predominantly middle class suburb of Leicester in the East Midlands). These three places reflect different aspects of the shifts highlighted in Census data. Between 2001 and 2011 Hackney's long history of ethnic diversity intensified as it became more diversely diverse: $36.2 \%$ of the London borough's population identifying as White British, $16.2 \%$ as 'other white', $11.4 \%$ as black African, $7.8 \%$ as African-Caribbean, $6.4 \%$ as South Asian and 5.6\% as Turkish, Cypriot or Kurdish (Neal et al., 2015b). In Milton Keynes the proportion of black and ethnic minority people doubled to $26.2 \%$ of the total, while in Oadby the share of the population identifying as White British declined by $23 \%$, at the same time as those identifying Asian/Asian British grew by 56\% (Leicestershire County Council, 2013; Milton Keynes Council, 2014).

One central focus of this research was the experience of young people in urban educational institutions, referred to as colleges in what follows (a school sixth form, a sixth form college and a further education college), populated by ethnically and class mixed groups of young people. Most of those we interviewed were aged between 16 and 18 years, although in the further education college the age range was slightly extended. It is recognised that young people are associated with inter-ethnic 'crossings'; with cultural openness but also with cultural defensiveness (Back, 1996; Harris, 2013; Hewitt, 1986), and it is this ambivalent openness, and its relationship to broader identity formations, which interest us here.

If, as Massey and others argue (Massey et al., 1999), the urban experience is defined through its intensity and the juxtaposition of difference, then colleges are quintessentially urban spaces, because of the ways in which they bring people together from a range of different backgrounds, requiring them to interact in mundane as well as sometimes more active ways. They are a particular expression of Massey's wider evocation of cities as the places 'where different stories meet up' (Massey, 1999: 134). Schools and colleges are a central aspect of the everyday, routine lives of the young people who attend them, providing opportunities for learning, meeting, being with others in the milieu of happy and not-so-happy encounters that shape college sociality (Hollingworth and Mansaray, 2012). In this context, young people are 'thrown together' in the way that Massey suggests is characteristic of urban places (Massey, 2005).

Colleges are worldly, emergent places in their own right buzzing with the rhythms of lives and flows of people and objects that coalesce around education and learning. They are shaped and stirred by proximity and encounters. Schools and colleges provide young people with space to make their own place (in the world), but students can also be made to feel out of place through their interactions with others. College occupies a large chunk of students' lives and if living multiculture is produced through practices, then colleges play a crucial role in framing the practices of young people as they encounter one another.

At the same time, although colleges and schools are often clearly demarcated, bounded, even fenced-off places, they are 
also fundamentally defined by the wider urban settings within which they are located, embedded in social relations that stretch beyond those institutional boundaries (Noble, 2013). They are necessarily connected into places that stretch beyond the colleges into the homes and communities from which their students come, and which themselves are, as Amin puts it, 'relationally constituted, a space where multiple geographies of composition intersect, bringing distant worlds into the centre of urban being and projecting the places outwards through myriad networks' (Amin, 2012: 64). In that sense, too, they are urban institutions, woven into a complex and extended urban fabric. In other words, not only do the colleges have to be understood as (urban) places in their own right, within which social interaction occurs and social relations are made up, but they are also placed within these wider networks and sets of connections within and beyond the city.

In that context, this paper focuses on the 'local micropolitics of everyday interaction' (Amin, 2002: 970) and, like Harris (2013), our concern is not only with the comfortable, mundane flow of social relations, but also with uneasy moments, tensions and conflict. Our research is heavily underpinned by participant observation of everyday, (un)easy interaction in canteens, corridors and common rooms in addition to interviews and repeat in-depth discussion groups that explore accounts and experiences of multiculture (Duneier and Back, 2006). Members of the research team visited the colleges, which have been given pseudonyms in what follows, at different times of the day, week and academic year, observing interactions, happenings and events. Interviews were conducted one-to-one with students who were then formed into groups of between 6 and 12 which met three times over a six month period.
The students (all given pseudonyms) who participated in group discussions are briefly introduced in Table 1, which begins to illustrate the diversity of the students (and their life experiences), but also how they identify themselves (to others) hooking into groups that get labelled into familiar ethnicity (and occasionally other identity) categories. We also met with senior staff in all three colleges. We used ethnographic methods so that we could observe and compare college life and group dynamics and listen to individual experience and biographies (see Bennett et al., 2015).

All three colleges are ethnically diverse, although in different ways and to different extents. Tyssen Hill College in Hackney is a sixth form college with around 1500 students, mostly aged 16-18 years, and, according to Ofsted (Office for Standards in Education, Children's Services and Skills), in 2012 ' $80 \%$ of its students were of black and ethnic minority heritage'. Tyssen Hill attracts students from not just Hackney, but from across east London. The students who took part in the research (see Table 1) reflect the super-diversity of the College in terms of ethnicity, class, religion, language, migration status (and more besides, Vertovec, 2007). Most were first-generation migrants to the UK and had not lived in London for long. The group felt very mixed in terms of class with Amrita and Zhi the children of doctors whilst others lived in households with noone in regular paid work. Not all of the young people lived with a parent and family/home life stretched across continents. Uplands College in Oadby is a coeducational comprehensive school for 14-19 year olds, with over 2000 pupils, more than half of whom have minority ethnic backgrounds. Around half of its 2000 pupils are in the sixth form, and about $90 \%$ of these go on to university. The predominantly middle class identity of Oadby is reflected in 


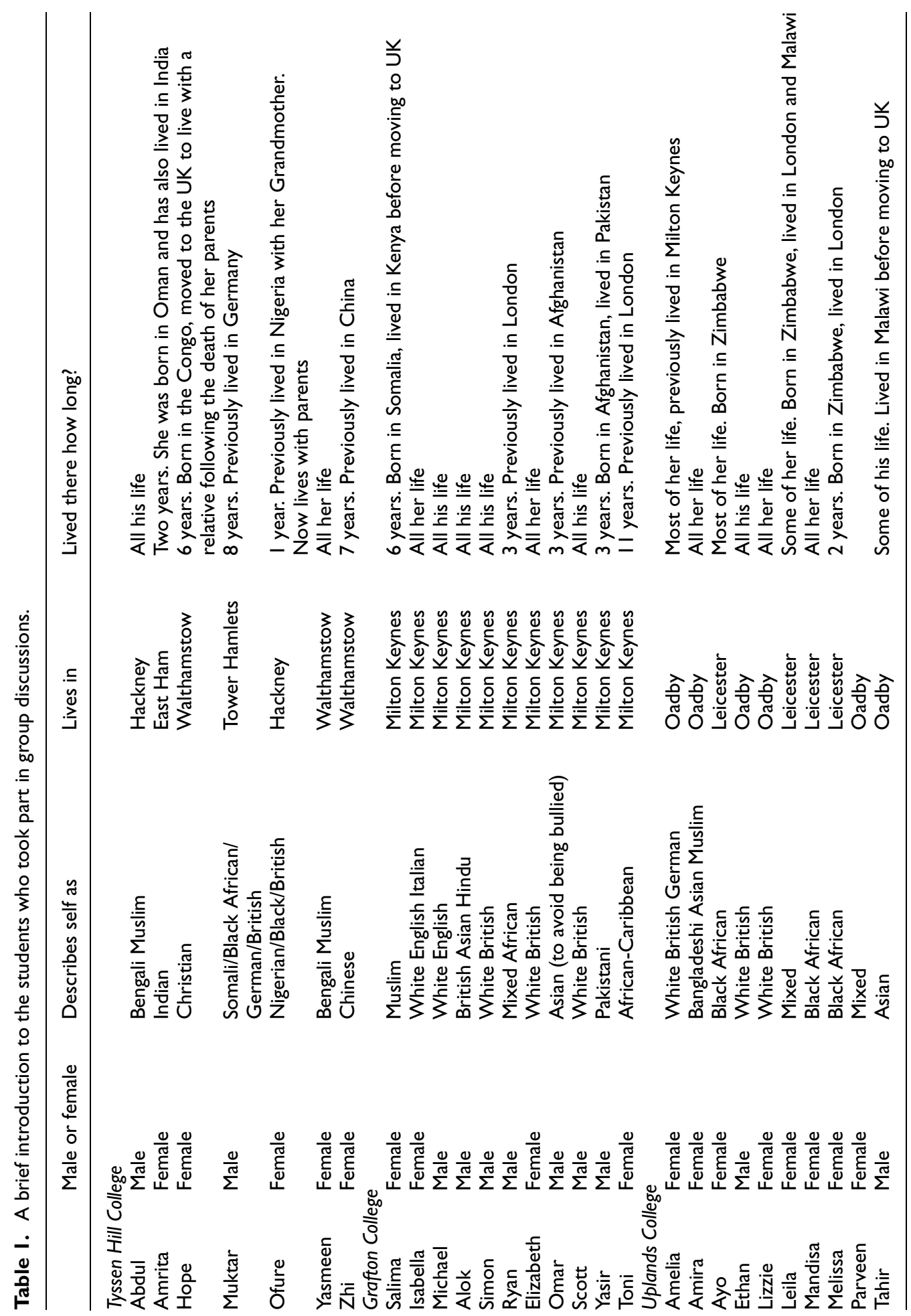


Uplands College and the aspirations of its students. Most of the students we interviewed who lived in Oadby were children of self-employed business owners. Young people travelling to Uplands from Leicester were more mixed in terms of class. Grafton College in Milton Keynes is a large general further education college on three sites with nearly 3000 full-time students aged between 16 and 18 years, and it also has around 400 full-time students over the age of 19 as well as a large number of part-time students. Unlike the other colleges, it offers a large number of apprenticeships and vocational courses. Of the full-time students, $26 \%$ are from black and minority groups. Three of our research participants were in their 20 s and we had a mix of people studying either for A levels or on vocational courses.

The paper is organised into three main parts. The first section considers the spaces of institutional life within the colleges, as urban spaces that mediate student sociality and formally engage with multiculture. The second part explores the ways in which students actively use and negotiate college space, reflecting on some of their skills and competencies for managing (un)easy relations. If the first two sections focus on the colleges as urban places, as institutional spaces within which everyday lives are negotiated, the third reflects more directly on the relationship between college life and the wider urban settings in which the colleges are placed.

\section{The framings of institutional life}

There are three overlapping aspects to the institutional practices of the colleges: the first relates to the emphasis on student educational success which is apparent in each case; the second to the explicit celebration of cultural diversity; and the third to the spaces of interaction and negotiation within the colleges. While each implies a rather different framing of multiculture, they come together in familiar ways as part of the process of regulating (and defining) the urban spaces of college life.

Before students step foot in them, colleges emphasise the end point of qualifications and exam success. Certificates - white sheets of paper listing qualifications - are the focal point. In other words there is an expectation of shared aspiration and shared measures of success. Open a prospectus or look around the walls of colleges and pictures of smiling students posing with these white pieces of paper are apparent. Routes are mapped out for current students towards these objects, in the branding of schools, on notice boards and on television screens that encourage students to 'aspire, study, achieve' (Tyssen Hill College). The talk (and the celebration, for example at Grafton College's annual awards ceremony) is framed by shared ambition and tales of individual success, often against the odds.

To achieve these certificates, students are directed by staff, timetables and curricula and supported by a range of pastoral services and resources because:

We believe that everyone has the ability to achieve, to be happy and to thrive and we are committed to creating the best possible environment to support you to do and be your best! (Tyssen Hill College Prospectus [pseudonym] 2013-2014: 5)

The language of aspiration is one in which students are imagined as a more or less unitary category, with ambitions defined through a language of certificates, assessment and examinations. But in the context of urban multiculture, this is refracted through a language of diversity. The institutions' formal multiculturalist positions are set out in prospectuses and online information (and each also has its own policy for dealing with racism). Uplands College's 
2013 Prospectus emphasises that 'students come from a range of cultural, ethnic, linguistic and faith backgrounds which has greatly enriched our daily college experience'. In its Prospectus 2012-2013 Tyssen Hill College refers to the events held in its canteen, 'where students relax, eat, study and take part in events to celebrate our diversity'. Grafton College's 'proud record of championing diversity and equality' is stressed in the Principal's introduction and all three colleges have been formally and publically recognised for embedding the needs of a diverse student and staff body into their core work.

All three prospectuses are alight with smiling faces, posing for the camera. In the Tyssen Hill Prospectus and the 2012 Student Newsletter, there are photographs celebrating occasions such as Diwali, Turkish Republic and Nigerian Independence Days, Cuba Day and Christmas. These events, while often requested by students, are organised by staff and 'combine music, dance and food to celebrate different cultures'. Ahmed (2009) powerfully and persuasively questions the diversity agenda, like that set out and celebrated in college prospectuses, newsletters and organised events because of the way in which it invites happy performances from those designated as representing diversity, performing at events and smiling for photographs. As a result she argues, 'to embody diversity is to be prohibited from even speaking about racism' (Ahmed, 2009: 51, see also Ahmed, 2010). But it is also important to explore the slippage spaces, between the formal diversity positionings of the colleges and the unruly, spontaneous reworkings undertaken by those involved.

At a lunch time event (proposed by students) to celebrate Nigerian Independence Day in the canteen at Tyssen Hill College, students and staff were preparing for a troupe of visiting Nigerian musicians and dancers. The canteen was serving Nigerian food, face and hand painting was happening at a table. The celebration of independence was embodied in performance, reinforced by young male dancers and drummers running into the crowded room, barefoot, in costume. But as the college celebrated Nigerian Independence, the purpose of the event slipped from view as people got mixed up in moments and encounters involving the embarrassment and hilarity of being pulled to the front to dance, falling over one another to escape the grasp of another or watching a friend or teacher perform. Members of staff gave up trying to keep students seated. Pupils stood, took photographs of the event and crowded round the dancers. Whilst events such as this can involve uneasiness over who and what is excluded and how people and nation are identified (see, for example, Youdell, 2012), they also generate opportunities for unanticipated and unusual encounters with unexpected others, unsettling the usual rhythms of daily college life and patterns of social interaction.

In many respects college space encourages institutionally approved mixing and interaction with others. Showing us around the college the Principal of Tyssen Hill talked about the importance of having one central space where everyone went, with few other spaces available where students might separate out, congregate in groups. 'The canteen' is a large space, has a glass ceiling and natural light, numerous entrance points, with its 'Diversity' kitchen to one side where food is bought and round tables where students sit. Grafton College and Uplands College also have large spaces which encourage sociality, and one Grafton student emphasised the value of spaces where 'you can sit and just chill while you're on your break' (Isabella, 1st group discussion, Grafton College).

These institutional spaces are the focus of active management by college staff who seek to make the communal spaces safe for student interaction. In Grafton (perhaps 
reflecting a contrast between further education (FE) and school spaces) this is handled relatively informally on one campus, since the café space is one through which staff and students pass on a regular basis, while on the other active attempts have been made to open up the use of the common room in response to concerns that it has been dominated by young men. The management process is more overt at Uplands, where teachers with walkie talkies cruise round the Sixth Form Centre during lunch time. In Tyssen Hill regulation and discipline is similarly overt, teachers and staff police behaviour and the canteen is overseen by a man who seems to be popular with the students, walking around, talking to them, stopping to ask students to take down their hoods, take their feet off the tables. The canteen was often a bustling, but relaxed space, but it also sometimes:

felt slightly edgy and it was not hard to imagine a spark leading to some kind of incident - perhaps that was why the school employed a man whose job it seemed to be to bark orders at the students during break time - the 'bad cop', as (another researcher) called him. At one point I was chatting to a group of students as they were playing cards, and he came over and swept all of the cards onto the floor. It was the end of break, when card-playing was no longer allowed. (Field notes 18 October 2012)

As well as working as regulated and highly managed environments these central, ordered, communal spaces of college were contexts in which skills to negotiate tensions and conflict developed, even flourished, and it is those we now consider.

\section{Negotiating college space: \\ At-ease and uneasy multiculture in place}

Colleges have formal and informal rules of behaviour, which help to define them as places, at least while they are occupied by students and staff who understand those rules. But the spaces of college life are not simply institutionally given. They are shaped by those who use them. Multiculture is actively negotiated by young people through embodied practices, which includes what students wear (none of the colleges had a school uniform), who they hang out with and where they sit during breaks. It also involves cultural learning and skills as they go about college and meet others, requiring more active engagement than Goffman-style civil inattention (see Jones et al., 2015).

While Hollingworth and Mansaray (2012) confirm that the mix of students in the sixth form of an urban (London) school in which they undertook research ensured that 'some degree of cultural learning' took place (Hollingworth and Mansaray, 2012: 6.3), they are sceptical about the extent to which this resulted in mixing or the development of friendships across difference. Their arguments are persuasive but, there is a danger that a focus on 'actual' mixing or a search for cross-cultural friendship may understate the significance of the ways in which unpanicked multiculture is (more modestly, perhaps) negotiated in practice, and it is on this that we focus.

The experience of the café area at Uplands College exemplifies some of the ways in which space was used and negotiated by young people. There were identifiable, and, as described by the students, ethnically defined tables. A group of black African women sat at a table that was separate from tables of ('bad man') Asian students, who sat separately from tables of white English 'boys'. Of course these groups were actually rather diverse (in terms of birthplace, transnational attachment, migration history, language, religion and class, etc.), but ethnically defined tables happened in the process of (self/other) labelling up (Harris, 2013). The sorting of tables was also 
expressed in different sets of division and identification, particularly along lines of gender, as well as between 'geeks' and others, so the sorting itself is rarely fixed and may even provide the basis for forms of interaction and sharing. This was summarised to us (in amused tones) in one of the ethnically mixed group interviews involving Ethan who identifies himself as White British and Mandisa and Ayo who identify themselves as black African:

Ethan: The African table, they sit in the corner and they, they're so happy, it's crazy, they're all just laughing and shouting [laughs].

Mandisa: Yeah. That area over there, that's called the bad man corner, where all the Asians sit. And then round there, there's a mixture. And here there's like sometimes the geeks and that ...

Ayo [one of those who sits at 'the African table'] reflected on how they were perceived:

Ayo: They seem feisty and loud and that. And then the other table might not like that so they're like, 'Oh, let's not go there because ...' they get intimidated in other ways because they've got such strong characteristics ...

Ethan: Because you're all quite close as friends already, so anyone who joins will feel like they're intruding or something because they're not as close.

However, this self-identification also provided a basis for forms of interaction, as Ayo explained:

there's another table of like a lot of white boys that you might see around, we usually mix with them ... So sometimes you see a - like, shadowing two tables because there's just so many of us around one table ... they've been like most open to us because a lot of people find our personalities really overbearing, really loud, eccentric ... They're taken aback a bit but with them they're like - they're mature, they're like 'Yeah, yeah, yeah, yeah, you lot are alright'. (From interview with Ayo)
The coming together of groups happened around crude identifications of ethnicity (and gender), through the music they listened to, fashion and clothes worn by students (leggings and tops for British Asian women at Uplands for instance), arriving in the common room or canteen together, caught up in conversation about something or other, seemingly a bit oblivious to others around, as the group moved towards an available table (sometimes their 'usual' table). Groups at tables grew as others were texted and joined in. There were sudden bursts of laughter at tables, heads thrown back, as students chatted with one another. Explaining why students sharing some common ground around ethnicity grouped together, differentiating themselves from others in the process, Tahir (who describes himself as Asian) said:

You relate to the person more if they're from your background ... You can relate to them ... and you can have your own private jokes. They're not private but, like, jokes that you both understand 'cause you both grew up with it, so it makes a better conversation as well. (Tahir, 2nd group discussion, Uplands College)

However, it would be wrong to suggest that students neatly separate themselves into 'ethnically' defined groups around tables in canteens and common rooms at lunch times. Students also moved between groups. It happened around tables of students 'shadowing' one another but was also prompted by the confident ones who never seemed to settle as they moved around the room, chatting to friends, flitting and flirting around tables. Communal areas flowed with continual movement. Tables of seated students moved too, expanding, shrinking, chairs added or taken away, as students called out to people at neighbouring tables, 'adopted' others (so a white English girl could sit at the 'black African' table), talked across tables, came and went. 
The complexities and ambiguities (sometimes awkwardness) involved in negotiating around multiculture were palpable in conversation with students. This was clearly reflected, as Tahir's comments above suggest, in how 'jokes' were used. Young people used joking and humour to develop feelings of alliance and affiliation with others (Gundelach, 2000), but stressed the importance of understanding with whom and in what contexts joking relationships might be developed. The tensions around joking can be seen in the following extract from one of our group interviews at Tyssen Hill College:

I find this a lot with my friends, like we make jokes amongst each other about our races but in a, like we're friends, and it's kind of like when other people are around you have to kind of bite your tongue and be careful what you say just in case they get offended. Or when it's amongst friends it's like it's okay because we do it to each other and we know it's on a you know, jokey basis. So I guess in that sense when you're around other people you have to be careful ... every culture has their own like little stereotype so you tease them about their stereotype and they tease you back about your stereotype, and when it's amongst friends it's okay. And even if you do it as a joke to somebody else who you don't know that well, you just don't know if they're going to take it in that way or not or if they'll get offended. (Yasmeen, 2nd group discussion, Tyssen Hill College)

The process of active (if rarely articulated) negotiation is apparent here: some jokes are deemed acceptable if uttered by friends or people with whom students are on friendly terms, but would be unacceptable in other contexts (Billig, 2005). Some students indicated that joking and stereotyping like this was possible because they speak 'on the same level' (2nd group discussion, Uplands College), talk 'in the same manner, humour, everything' (2nd group discussion, Uplands College). They were skilfully aware of how joking tanks when the balance of power feels unequal and individuals do not feel 'on the same level' (Lockyer and Pickering, 2008). This highlights the need for careful interactions as students figure out how well they 'know know' (Uplands College, 2nd group discussion) the people they are with and how well a joke will go down with them. In all three colleges students felt doubly selfaware, wary of others and watchful of reactions to their jokes.

Sometimes students pre-empt others, making jokes about themselves, such as when Yasmeen talked about Bengalis 'liking fish' (Laughter - 2nd group discussion, Tyssen Hill College) or Zhi referring to herself as 'Ping Pong' (1st group discussion, Tyssen Hill College). It might be that as students were repeating stereotypes, they were mocking these and the prejudices associated with them (Billig, 2005). Perhaps too they were skilfully drawing attention to the social superiority that accompanies the stereotyping of others, the power relations that mediate ridicule and laughter and the discourse of racism that pervades stereotyping - as in 'you're all the same' (Billig, 2005). But even in this context some sort of defensive awkwardness is apparent - joking about a stereotype also becomes a means of avoiding the stereotype being mobilised negatively against the individual concerned.

Jokes were experienced in a range of ways by different students - as funny, boring, painful, awkward - 'You feel a bit awkward' or 'out of place' (2nd group discussion, Uplands College). One consequence of handling stereotyping and ridicule in this way apparently laughing off the 'jokes' - may be to make it more difficult to engage with some of the micropolitics of power and the subtle ways in which forms of racism may be reinforced. As students told us about the joking around stereotypes that happens in college, there was also a sense that whilst laughing, some were also revealing frustrating, painful 
and uncomfortable experiences, as they are marked out, whilst others, often White British students, escape such attention or even become invisible as an ethnic category (Pickering and Lockyer, 2005).

But 'whiteness' and even class do not always provide protection. Amelia, who is White British/German with a middle class background, told the story of her own experience with other white students:

shouting heil Hitler down the street and that's ... [Laughter in the group] Well, this is down corridors. I'm just like, no ... it was quite hurtful for me because ... this simply wasn't seen as racist (by other students). Racism towards other cultures and other religions, other skin colours, that was seen as really bad but it was okay to be racist towards me because I'm also white. (Uplands College, FG2)

Although laughing along with the others, Amelia was unhappy with the way in which she felt she had been stereotyped and was keen to point out that her 'whiteness' meant that her experiences of what she describes as racism were not taken seriously by fellow students (Hewitt, 2005).

Another key skill that students discussed with us was that of knowing how and when to exercise restraint. On the face of it, restraint could also be a tactic for avoiding pain and allowing the subtleties of racism to persist, but young people also revealed the ways in which it had the potential to enable dialogue and cultural learning especially when faced with ignorance. It was an important skill in the process of students getting to 'know know' one another. In his book Together, Richard Sennett (2012) writes about some of the skills that need to be crafted for living together that involve restraint or 'employ(ing) minimum force' (2012: 208) in the face of ignorance and (resistant) others not listening well. In colleges, young people drew our attention to the restraint they employed to handle the ignorance of others. Melissa, a black African student at Uplands College, said:

Yeah, I get an awful lot of stereotype. Like first impression, because I change my hair quite a lot, like one minute I'll have an afro, next minute I'll have a different colour. Everyone thinks I'm Caribbean for some reason. And because I had a piercing here, you know, they're like, 'Oh she's Jamaican, she's this', but when they actually find out, 'No, I'm Zimbabwean', they're like, 'you what? How? Which one of your parents are black?' And I'm like, 'No, they're both African'. It's awful to have to start explaining everything because no-one ever believes me the first time round. It's quite annoying ... It's quite frustrating ... I don't mind actually. I quite enjoy my stereotypes that I get, because I know that's not me. I really enjoy getting stereotyped. Like when I first moved to Uplands a few of my friends, my current friends, they said first impressions they thought I was quite bitchy, but now they know that I'm a really nice person, so I'm like, well I quite enjoy the stereotypes because I know I'm not like that.

In the above extract Melissa points out how she has to repeatedly explain herself whilst being stereotyped by others, who she now considers to be her friends. Although, this stereotyping is 'awful', 'annoying' and 'frustrating' she is probably what Sennett (2012) refers to as skilfully restrained in her responses to her peers, as they see it - far from 'bitchy' and 'really nice', even when they do not believe her. Whilst easing relations with their peers, restraint was sometimes employed at a cost to themselves. This is a particular concern when restraint is employed because students do not think their complaints will be taken seriously and/ or do not trust institutions to help them. Ayo, a Black African student at Uplands College, said:

It's not even - it's not even, like, [I] tolerate racism. Like I've just learnt to not care - at the end of the day, I'm here to do what I need to 
do. I'm not here for you to tell me that I'm black or white, Asian, Polish, whatever. I don't care. Like I'm black, I've got to get used to it [laughter]. I can't change my colour, so ... It's just one of them thing's you've got to accept, like you've got to put up or shut up ... So it's just something I need to shrug off.

Fears of institutional inaction, or worse, were a reality for a student who complained about racism in another college setting. Whilst Toni (a young African-Caribbean woman) noted the way in which Milton Keynes was changing and identified the extent to which it was an easier environment for her than it had been, she nevertheless complained about how she was positioned in college, following a racist comment from another student, who denied it when it was investigated. The following term when she was placed in the same class as the student, her tutor asked whether Toni was going to cause any trouble because of this. Toni said to her tutor:

\begin{abstract}
'Well, why would I cause any trouble? I'd just walk away, like I did the first time.' And she's gone, 'Oh, I didn't think you'd be like that. I thought you'd start fighting,' and she gestured as if to say, like, did boxing gestures. And I just thought, 'That's a bit stereotypical, what are you basing that thought on? You've never taught me, you've never interacted with me', so exactly what was she basing that, 'I thought you would fight' on?
\end{abstract}

Toni had walked away from the student's racist comment and looked on as her tutor stereotyped her, keeping her thoughts to herself. In the frustration Toni revealed to us, there is undoubtedly an emotional cost to individuals like her who employ restraint to ease relations with/for others.

\section{College life in the urban}

The negotiated spaces of college life are experienced and shaped by students who are stitched into wider urban social worlds. Colleges bring together young people from different backgrounds and with different worldly experiences on a daily basis, and their positioning within the networks of connection and disconnection that define the urban are apparent in the college setting too. Much of the evidence presented earlier confirms this, as students draw on their wider senses of identity (in terms of ethnicity, class and gender) to position themselves in the college setting. It is impossible to ignore the sense of connection to elsewhere, understood through family and other networks, which flows through the language mobilised in the interviews discussed above, even as new shared spaces are being put together. The experiential worlds of the young people we spoke to and observed were constituted and framed by the relational understandings of urban life identified in the introduction.

The young people involved in this project were embroiled in the attitudes and expectations of family, household and home life, which often stretched across countries and continents. Students embodied 'complex forms of conduct located in ensembles of relations and spaces' (Noble, 2013: 181) and some were explicit about how these 'ensembles' affected their activities and experience of College. Salima, for example, is a mature student (in her early 20s) at Grafton College. She has a child with a partner who lives in South Africa and she and some of her family recently moved to the UK from Kenya. Compared with when she lived in Kenya, she felt that her father was very strict since moving to the UK. Reiterating her father's words, Salima said:

You don't hang out after school. You go to school and you come back home. You wanna hang out it's with family members, then come home, or you go out as a family and stuff like that for girls. And you find that we don't really 
keep close friends because of that. (1st group discussion, Grafton College)

If these more extensive interpretations of the urban are important to any understanding of the making up of college life it is nevertheless also important to recognise the significance of the more immediate (or proximate) urban context in which they exist. In our discussions with students, feelings about college were often justified in relation to where they lived. References were frequently made to college feeling like a 'safe' place, especially when compared with the place where they lived or near where college was located. Students at Tyssen Hill made reference to high levels of crime and their fear of knife crime in particular. The relationship between school and place can be a complex one in which reputation of college and of place collide uneasily (Hollingworth and Archer, 2010). College space is a protected and 'safe' sociable space in which young people are able to learn from and work with each other, while acknowledging tensions and awkwardness, but the way in which those experiences translate into their other worlds (and other places) is not always straightforward (see also Anderson, 2011, who distinguishes between the protected space of the 'cosmopolitan canopy' and the less protected spaces beyond it). The Principal of Tyssen Hill College made reference to the large number of students who lived alone, away from their families, implying that college was the closest thing to support that they had in their lives providing an escape from loneliness.

The confidence with which the possibilities of multiculture were articulated varied significantly between locations. Tyssen Hill is located within an area of London whose population is marked by its diversity, and its student body is drawn from a wide catchment across the neighbouring boroughs. In a sense, therefore, it is defined by the diversity of its student body and (as we have seen) this is articulated clearly in college literature as well as being understood by the students themselves. Some students self-consciously sought to escape the attitudes and practices of family and household members, performing very differently in college from the way in which they present themselves outside it. For them college was a place where they could mix with others, be themselves, or shape space to be themselves, and escape the 'pestering' of parents and their rules about, for example, wearing 'traditional clothing' to friends' houses ‘blah blah blah' (Yasmeen, 2nd group discussion Tyssen Hill College). The confident management of the complexity implied by this set of relationships was a characteristic of students at Tyssen Hill. If college life was a space in which it was possible to escape from the constraints of community and family pressure, the dispersed spaces of the city also meant that outside college it was possible to move back into existing networks rather than maintaining college-based friendships.

At Uplands, a degree of confidence among students was also apparent, but in a very different urban context, namely one defined through a more apparent middle class identity and a much more limited catchment area for students. The focus of the institution is on A level success and this helps to shape its identity. Here we were told of complex negotiations around student interaction outside the school, in which coming together across apparent community divisions was enabled in some contexts but not in others. So, for example, Tahir notes the extent to which his friendship network is largely made up of Asian young men (both within and outside college) but he also stresses the extent to which it crosses divisions between Muslims (he is Muslim), Hindus and Sikhs. And he comments that sometimes a wider group is involved, 'We go out, all different types of friends and everyone just sits with everyone. But like, it's not dominated by one - one, like, culture, so it's a variety of all'. 
In the case of Grafton College, however, and in the wider context of Milton Keynes, it was apparent that learning the language of multiculture is a relatively new experience. Simon, who is White British, spoke positively about the world in which he found himself, but from a position in which his own white Britishness was clearly seen as the norm:

No, it's not an issue. I've had, um, I've had many friends that have been coloured or, um, I've got a few Asian friends or a few, um, Pakistani friends; I've got, um, a few black friends; I've got a Chinese friend; I've got a Polish friend. So it's all, sort of like, there and mixed in together, so I'd never say that I'm rude about someone else's, like, colour or, um, eyes, or anything like that, so yeah.

\section{Concluding thoughts}

With the broad aim of exploring the skills and competencies that people develop to live everyday multiculture, we have considered the practices and experiences of young people in three colleges with an ethnically diverse student body. Being in education environments means that young people are more routinely exposed to significant levels of often intense cultural and social difference. Whilst much effort is put into directing and fostering aspiration amongst students, colleges also put considerable energy into encouraging them to engage with, and recognise, others as they celebrate diversity, host events and organise space. Sometimes these institutional practices have unexpected interruptions and consequences. Our study has shown that students engage in difference in often ambivalent but always 'live' ways, going beyond celebratory multicultural positions in ways that unsettle them and the usual rhythms of college life, prompting convivial interactions, as well as prompting (less) comfortable experiences.

Whilst colleges have rules and regulations that define them as multicultural places, the outcomes are not institutionally given, but defined by those who operate in them. Difference was actively negotiated in college and depended on the skills, competencies and knowledge of students living multiculture. So, for example, in the case of joking, the competencies involve know-how - what can be said and with whom - and the skill of practising restraint (for particular students) - holding back and 'biting your tongue' for example in the face of stereotyping (Sennett, 2012: 208). Knowledge involving 'know knowing' people and when it is appropriate to joke with whom was often identified by students, but rarely explained. Sometimes students 'know' others enough to joke around with them because they think they share an ethnic heritage, but not always. What is important for 'know knowing' is the accumulation of those moments when usual routines and rhythms are (briefly) unsettled as students fleetingly encounter one another as they move between tables, joke and banter across tables and attend college organised events that generate unexpected situations.

The social worlds that embody students define how they relate with others (and authority figures) and experience and (re)produce college. College does not simply frame practices but is refracted through students and their urban places. The places in which the colleges were located and their histories regarding ethnic diversity were reflected in student practices and experiences at college. Milton Keynes, for example, was identified by students as a significantly changing place in terms of its ethnic diversity and this was reflected in their practices and uncertainty regarding the language of multiculture. Whilst the locations of colleges were significant in the social worlds of students and (less) comfortable experiences at college, these worlds also involved points of connection that cut across cultural difference regarding (escaping) the clutches of parents and home life, youth culture including 
music, fashion and gaming, dread of exams and affection for college.

Whilst this paper contributes to work on unpanicked multiculture, it also opens up awkward moments, the power relations involved and the emotional challenges of living multiculture. At-ease and everyday interaction does not necessarily mean the process is easy. Nor does it mean that it is possible to identify some sort of post-racial urban utopia. On the contrary the negotiation involved is often more complex than it sometimes appears or is articulated by those involved. It may seem obvious to say that colleges are places of learning, but what is apparent is that the formal processes of learning, delivering the certificates, is accompanied by more informal processes in which students manage and negotiate difference. Important to these informal processes are the urban places in which colleges are located, the social worlds that students embody, college (micro)space and the accumulation of encounters that generate knowledge and competencies and invent college space. Colleges are key sites within which urban multiculture is experienced and through which it is defined.

\section{Acknowledgements}

We would like to thank all the students and college staff involved in our research, especially those people we interviewed, who took part in our repeat group discussions and permitted us access to their sites and premises. We could not have done this research without their help and we are so very grateful. All names have been changed. We would also like to thank all the researchers and research consultants involved in this project. These include Kieran Connell, Hannah Jones, Christy Kulz and Akile Ahmet. Big thanks to the editor and anonymous referees for their helpful comments and suggestions.

\section{Funding}

We would like to thank the ESRC for funding the research 'Living Multiculture: the new geographies of ethnic diversity and the changing formations of multiculture in England' (ES/J007676/1).

\section{References}

Ahmed S (2009) Embodying diversity: Problems and paradoxes for Black feminists. Race, Ethnicity and Education 12(1): 41-52.

Ahmed S (2010) The Promise of Happiness. Durham and London: Duke University Press.

Amin A (2002) Ethnicity and the multicultural city: Living with diversity. Environment and Planning A 34: 959-980.

Amin A (2012) Land of Strangers. Cambridge: Polity.

Anderson E (2011) The Cosmopolitan Canopy. Race and Civility in Everyday Life. New York: W. W. Norton.

Back L (1996) New Ethnicities and Urban Culture: Racisms and Multiculture in Young Lives. London: UCL Press.

Bennett K, Cochrane A, Mohan G, et al. (2015) Listening. Emotion, Space and Society 17: 7-14.

Billig M (2005) Laughter and Ridicule: Towards a Social Critique of Humour. London: Sage.

Duneier M and Back L (2006) Voices from the sidewalk: Ethnography and writing race. Ethnic and Racial Studies 29(3): 543-565.

Gilroy P (2004) After Empire: Melancholia or Convivial Culture? London: Routledge.

Gundelach P (2000) Joking relationships and national identity in Scandinavia. Acta Sociologica 43: 113-122.

Harris A (2009) Shifting the boundaries of cultural spaces: Young people and everyday multiculturalism. Social Identities 15(2): 187-205.

Harris A (2013) Young People and Everyday Multiculturalism. London: Routledge.

Heath A and Demireva N (2014) Has multiculturalism failed in Britain? Ethnic and Racial Studies 37(1): 161-180.

Hewitt R (1986) White Talk, Black Talk: Interracial Friendship and Communication Amongst Adolescents. Cambridge: Cambridge University Press.

Hewitt R (2005) White Backlash and the Politics of Multiculturalism. Cambridge: Cambridge University Press.

Hollingworth S and Archer L (2010) Urban schools as urban places: School reputation, 
children's identities and engagement with education in London. Urban Studies 47(3): 584-603.

Hollingworth S and Mansaray A (2012) Conviviality under the cosmopolitan canopy? Social mixing and friendships in an urban secondary school. Sociological Research Online 17(3). Available at: http://www.socresonline.org.uk/ 17/3/2.html.

Jivrav S (2012) How Has Ethnic Diversity Grown 1991-2001-2011? Manchester: Centre on Dynamics of Ethnicity/Joseph Rowntree Foundation.

Jones H, Neal S, Mohan G, et al. (2015) Urban multiculture and everyday encounters in semipublic, franchised café spaces. The Sociological Review 63(3): 644-661.

Leicestershire County Council (2013) Oadby Electoral Division 2011 Census Key Statistics. Research and Insight Team, Leicestershire County Council, May.

Lentin A and Titley G (2011) The Crises of Multiculturalism. Racism in a Neoliberal Age. London: Zed.

Lockyer S and Pickering M (2008) You must be joking: The sociological critique of humour and comic media. Sociology Compass 2/3: 808-820.

Massey D (1999) Cities in the world. In: Massey $\mathrm{D}$, Allen $\mathrm{J}$ and Pile S (eds) City Worlds. London: Routledge, pp. 99-156.

Massey D (2005) For Space. London: Sage.

Massey D, Allen J and Pile S (eds) (1999) City Worlds. London: Routledge.

Milton Keynes Council (2014) Milton Keynes Theme Report - 2011 Census Population and Migration. Research and Intelligence, Milton Keynes Council, April. Available at: http://www. mkiobservatory.org.uk/contact.aspx?id $=17850 \&$ siteID $=1026$.

Nayak A (2012) Race, religion and British multiculturalism: The political responses of Black and Minority Ethnic voluntary organisations to multicultural cohesion. Political Geography 31(7): 454-463.

Neal S and Vincent C (2013) Multiculture, middle class competencies and friendship practices in super-diverse geographies. Social and Cultural Geography 14(8): 909-929.
Neal S, Bennett K, Cochrane A, et al. (2013) Living multiculture: Understanding the new spatial and social relations of ethnicity and multiculture in England. Environment and Planning C: Government and Policy 31(2) 308-323.

Neal S, Bennett K, Jones H, et al. (2015a) Multiculture and public parks: Researching superdiversity and attachment in public green space. Population, Space and Place 21: 463-475.

Neal S, Mohan G, Cochrane A, et al. (2015b) 'You can't move in Hackney without bumping into an anthropologist'. Why certain places attract research attention. Qualitative Research 10.1177/1468794115596217.

Noble G (2009) Everyday cosmopolitanism and the labour of intercultural community. In: Wise A and Velayutham S (eds) Everyday Multiculturalism. Basingstoke: Palgrave Macmillan, pp. 46-65.

Noble G (2013) Cosmopolitan habits: The capacities and habits of intercultural conviviality. Body and Society 19: 162-185.

Nowicka M and Vertovec S (2014) Comparing convivialities: Dreams and realities of living with difference. European Journal of Cultural Studies 17(4): 341-356.

Office for National Statistics (2012) Ethnicity and National Identity in England and Wales 2011. Office for National Statistics. Available at: www.ons.gov.uk/ons/dcp171776_290558.pdf.

Pickering $M$ and Lockyer S (2005) Introduction: The ethics and aesthetics of humour and comedy. In: Lockyer S and Pickering M (eds) Beyond a joke: The limits of humour. Basingstoke: Palgrave Macmillan, pp. 1-24.

Sennett R (2012) Together: The Rituals, Pleasures and Politics of Cooperation. London: Allan Lane.

Valentine G (2008) Living with difference: Reflections on geographies of encounter. Progress in Human Geography 32(3): 323-337.

Vertovec S (2007) New Complexities of Cohesion in Britain: Super-diversity, Transnationalism and Civil-integration. Wetherby: Communities and Local Government Publications.

Wessendorf S (2014) Commonplace Diversity. Social Relations in a Super-diverse Context. Basingstoke: Palgrave Macmillan. 
Wilson H (2011) Passing propinquities in the multicultural city: The every encounters of bus passengering. Environment and Planning A 43: 634-649.

Wilson H (2014) Multicultural learning: Parent encounters with difference in a Birmingham primary school. Transactions of the Institute of British Geographers 39(1): 102-114.

Wise A (2009) Everyday multiculturalism: Transversal crossings and working class cosmopolitans. In: Wise $\mathrm{A}$ and Velayutham $\mathrm{S}$ (eds) Everyday Multiculturalism. Basingstoke: Palgrave Macmillan, pp. 21-45.

Wise A and Velayutham S (eds) (2009) Everyday Multiculturalism. Basingstoke: Palgrave Macmillan.

Youdell D (2012) Fabricating 'Pacific Islander': Pedagogies of expropriation, return and resistance and other lessons from a 'Multicultural Day'. Race, Ethnicity and Education 15(2): 141-155. 